\title{
Early changes in 25-hydroxyvitamin D levels and bone markers after monthly risedronate with cholecalciferol in Korean patients with osteoporosis
}

\author{
This article was published in the following Dove Press journal: \\ Clinical Interventions in Aging \\ 29 May 2013 \\ Number of times this article has been viewed
}

\author{
Ho Yeon Chung' \\ Jawon Koo' \\ Su Kyoung Kwon ${ }^{2}$ \\ Moo-IL Kang ${ }^{3}$ \\ Seong-Hwan Moon ${ }^{4}$ \\ Jin-Young Park ${ }^{5}$ \\ Chan Soo Shin ${ }^{6}$ \\ Byung-Koo Yoon ${ }^{7}$ \\ Hyun-Koo Yoon ${ }^{8}$ \\ Jae-Suk Chang' \\ Yoon-Sok Chung ${ }^{10}$ \\ Hyoung-Moo Park" \\ 'Department of Internal Medicine, \\ Kyung Hee University, ${ }^{2}$ Department \\ of Statistics, ${ }^{3}$ Department of Internal \\ Medicine, Catholic University of \\ Korea, ${ }^{4}$ Department of Orthopedics, \\ Yonsei University, ${ }^{5}$ Department of \\ Orthopedics, Konkuk University, \\ ${ }^{6}$ Department of Internal Medicine, \\ Seoul National University, \\ ${ }^{7}$ Department of Obstetrics and \\ Gynecology, Sungkyunkwan University, \\ ${ }^{8}$ Department of Internal Medicine, \\ Kwandong University, ${ }^{9}$ Department \\ of Orthopedics, University of Ulsan, \\ Seoul, South Korea; ${ }^{10}$ Department \\ of Endocrinology and Metabolism, \\ Ajou University School of Medicine, \\ Suwon, South Korea; "Department of \\ Obstetrics and Gynecology, Chung- \\ Ang University, Seoul, South Korea
}

Correspondence: Hyoung-Moo Park Department of Obstetrics and Gynecology, Chung-Ang University,

224-I Heukseok-dong Dongjak-gu,

Seoul, South Korea

Tel +82 27489969

Fax +8226381985 I

Email hmpark52@hanmail.net
Purpose: This study investigated the efficacy and safety of monthly risedronate, with and without cholecalciferol, on 25-hydroxyvitamin D (25[OH]D) levels and bone markers in Korean patients with osteoporosis.

Methods: A randomized, double-blinded, prospective, 16-week clinical trial was conducted in ten hospitals. A total of 150 subjects with osteoporosis were randomized to one of the two treatment groups: RSDM+ (monthly risedronate $150 \mathrm{mg}$ and cholecalciferol 30,000 IU combined in a single pill, $\mathrm{n}=74$ ) or RSDM (monthly risedronate $150 \mathrm{mg}$ alone, $\mathrm{n}=76$ ). We measured serum levels of 25-hydroxyvitamin D (25[OH]D), parathyroid hormone (PTH), and bone markers, as well as performing muscle-function tests at baseline and after 16 weeks of treatment.

Results: After 16 weeks, serum 25(OH)D levels significantly increased from 17.8 to $26.8 \mathrm{ng} / \mathrm{mL}$ in the RSDM+ group, but did not change in the RSDM group. The RSDM+ group exhibited significantly decreased serum PTH from 46 to $36.7 \mathrm{pg} / \mathrm{mL}$, while the RSDM group showed a tendency for PTH to increase from 38 to $40.6 \mathrm{pg} / \mathrm{mL}$. In both groups, serum bonespecific alkaline phosphatase and C-terminal telopeptide rapidly declined, with significance at 16 weeks; there were no significant differences between the groups.

Conclusion: A once-monthly pill of risedronate and cholecalciferol provided equivalent antiresorptive efficacy to risedronate alone in terms of bone turnover and improved $25(\mathrm{OH}) \mathrm{D}$ levels over the 16 -week treatment period without significant adverse events in Korean patients with osteoporosis.

Keywords: bisphosphonate, cholecalciferol, bone markers, 25(OH)D

\section{Introduction}

Many pharmacologic treatments for osteoporosis have demonstrated the ability to improve bone mineral density (BMD) and reduce fractures compared to placebo in randomized, controlled trials. ${ }^{1}$ Bisphosphonates are the most commonly used medication for treatment of osteoporosis because of their efficacy. However, osteoporosis is a chronic disorder that needs long-term treatment, and bisphosphonate nonadherence is extremely common due to its complexity and adverse events of medication. Most patients discontinue bisphosphonates for osteoporosis therapy within 1 year. $^{2}$ One strategy to address the problem has been to reduce the frequency of the dose of bisphosphonates. Nowadays, oral bisphosphonates have been developed as a daily, weekly, and monthly administration. ${ }^{3}$

Although there has been some debate on the optimal serum level of 25-hydroxyvitamin $\mathrm{D}(25[\mathrm{OH}] \mathrm{D})$ for skeletal health, vitamin $\mathrm{D}$ is important for bone mineralization and 
skeletal health. ${ }^{4}$ Vitamin D recommendation is an essential treatment modality for osteoporosis. However, despite physicians' recommendations, the percentage of regular vitamin $\mathrm{D}$ intake among patients with osteoporosis is low. ${ }^{5}$ Therefore, the development of a single-pill combination of bisphosphonates and vitamin $\mathrm{D}$ has been a subject of interest to improve patient compliance and vitamin D supplementation. Although a fixed-dose combination of weekly bisphosphonates and vitamin $\mathrm{D}$ has been introduced for the treatment of osteoporosis, ${ }^{6,7}$ no published data are available with respect to the efficacy of a fixed-dose combination of monthly medication. Therefore, this study was designed to assess the efficacy of once-a-month tablets containing risedronate $150 \mathrm{mg}$ and cholecalciferol 30,000 IU, compared to that of the monthly risedronate alone, in terms of correction of $25(\mathrm{OH}) \mathrm{D}$ level and reduction in bone turnover.

\section{Methods}

\section{Study design}

This 16-week, randomized, double-blind, active-controlled study was conducted at ten centers in South Korea to determine the efficacy of once-a-month, single pills of risedronate $150 \mathrm{mg}$ and cholecalciferol 30,000 IU. The trial was conducted between November 2009 and August 2010. The institutional review boards of the investigational centers provided ethical approval of the study, and informed consent was obtained from all participating subjects.

Postmenopausal women were eligible for inclusion if they had a bone mineral density T-score of $\leq-2.5$ at the mean lumbar spine (L1-4), femoral neck, or total, or if they had a T-score of $\leq-1.0$ with radiologic evidence of at least one vertebral fracture. Menopause was defined as the cessation of natural menstruation for at least 1 year and a serum follicle-stimulating hormone level $>40$ IU/L, with a reported hysterectomy. We excluded patients who had contraindications to oral bisphosphonates, such as esophageal strictures, renal failure, and low levels of 25(OH)D (less than $9 \mathrm{ng} / \mathrm{mL}$ ). Previous use of oral bisphosphonates and vitamin $\mathrm{D}$ were allowed, but a washout period was needed, depending on the duration of treatment. A 2-year washout period was needed for bisphosphonate users and a 3- to 6-month period was required for vitamin D users of $>200$ IU.

Participants were evaluated for eligibility by dual energy $\mathrm{X}$-ray absorptiometry and routine biochemical assay at each center, and their 25(OH)D levels were determined (RIA [interassay coefficient of variability $\{\mathrm{CV}\}, 10.8 \%$; intra-assay
CV, 9.4\%]; Diasorin, Stillwater, MN, USA). Patients were randomized into two groups: RSDM+ (risedronate $150 \mathrm{mg}$ with cholecalciferol 30,000 IU once monthly) and RSDM (monthly risedronate $150 \mathrm{mg}$ alone). All participants also received $500 \mathrm{mg}$ of elemental calcium supplements daily. A single-pill combination of RSDM+ was provided by Hanlim Pharmaceutical (Seoul, South Korea), and permission was granted by the Korean Food and Drug Administration Board Committee to conduct the clinical trial. Participants were not allowed to take any additional vitamin D supplements and were asked to limit sunlight exposure.

\section{Efficacy and safety evaluations}

The primary end points compared the changes in $25(\mathrm{OH})$ D levels at baseline and after 16 weeks of treatment. Secondary efficacy parameters included measurement of bone specific alkaline phosphatase (enzyme-linked immunosorbent assay, Meta BAP EIA kit [interassay CV, 5\%-7.6\%; intra-assay CV, 3.9\%-5.8\%]; Quidel, San Diego, CA, USA), serum C-telopeptide of type I collagen (electrochemiluminescence immunoassay, CrossLaps [interassay CV, 4.2\%-7.6\%; intra-assay CV, 2\%-5.8\%]; Roche, Mannheim, Germany), and serum intact parathyroid hormone (PTH) levels (immunoradiometric assay, ELSAPTH [interassay CV, 4.6\%; intra-assay CV, 4.3\%]; Cisbio, Sorgues, France), after 16 weeks of treatment at a central laboratory. Lower-extremity function was assessed using an 8-foot walking-speed test (8-foot walk test) and a timed test of rising from a chair and sitting back down (sit-tostand test).

Safety was monitored during the study with all clinical and laboratory adverse experiences. The patients were seen by the investigators during their week 8 and 16 study visits; adverse events could be reported in person or by phone at any time during the study.

\section{Statistical analysis}

All analyses were performed on an intention-to-treat basis. An unpaired $t$-test, Fisher's exact test and Pearson's Chisquared test were used to compare the differences between the treatment groups. A paired $t$-test was used to compare pre- to post-treatment differences within the same group. An analysis of covariance was used to compare serum PTH changes from baseline at week 16, since serum levels of PTH showed a significant difference between the RSDM+ and RSDM groups. Analysis was done via SPSS (version 13.0; IBM, Armonk, NY, USA). 


\section{Results}

\section{Patient disposition and baseline characteristics}

The disposition of the participants who were randomized to the study is detailed in Figure 1. We enrolled 150 participants (74 RSDM+ and 76 RSDM) in the study. The completion rate for the 16-week study was similar for the two treatment groups $(85.1 \%$ versus $85.5 \%)$. There were no clinically significant differences in the baseline characteristics between the treatment groups, with the exception of PTH levels (Table 1). The prevalence of vitamin D insufficiency $(<20 \mathrm{ng} / \mathrm{mL})$ was $77 \%$ and $69.7 \%$ in each group, respectively.

\section{Efficacy and safety}

After 16 weeks of treatment, the mean serum 25(OH)D level increased significantly from 17.8 to $26.8 \mathrm{ng} / \mathrm{mL}$ in the RSDM+ group, but did not change in the RSDM group (Figure 2). As shown in Figure 3, the proportion of patients with vitamin D insufficiency decreased significantly in the RSDM+ group from $77 \%$ to $14.9 \%$, but increased in the RSDM group from $69.7 \%$ to $79.7 \%$. There was a significantly smaller proportion of patients with $25(\mathrm{OH}) \mathrm{D}$ level $<15 \mathrm{ng} / \mathrm{mL}$ at 16 weeks with RSDM+ $(1.5 \%)$ when compared with that of RSDM alone (63.8\%). The increase in 25(OH)D levels of the $\mathrm{RSDM}+$ group was greater in vitamin D-insufficient patients
(Figure 4). Furthermore, the level of $25(\mathrm{OH}) \mathrm{D}$ decreased in patients with $25(\mathrm{OH}) \mathrm{D}$ level $\geq 30 \mathrm{ng} / \mathrm{mL}$ at baseline.

In the RSDM+ group, a significant decrease in serum PTH was observed compared to the control group. No change in serum PTH was noted in the RSDM group compared to those at the baseline level. There was also a significant decrease in serum calcium for the RSDM group. Serum phosphorus significantly decreased in both groups. The bone turnover markers bone-specific alkaline phosphatase and carboxy-terminal collagen cross-links (CTX) decreased significantly compared to the baseline level, although no differences were observed between the two groups (Table 2).

There were no improvements in the 8-foot walking or sit-to-stand tests, which we used to assess lower-extremity function after the 16-week vitamin D supplementation (data not shown).

A similar number of subjects reported adverse events in each group: $58.1 \%$ in the RSDM+ group and $57.8 \%$ in the RSDM group (data not shown). No serious adverse events were reported. Muscular and gastrointestinal discomforts were the major drug-related adverse events in both groups (35.1\% and $22.9 \%$ of RSDM+ versus $30 \%$ and $19.7 \%$ of RSDM, respectively). Among muscular discomforts, myalgia was the most common symptom in both groups $(35.1 \%$ of

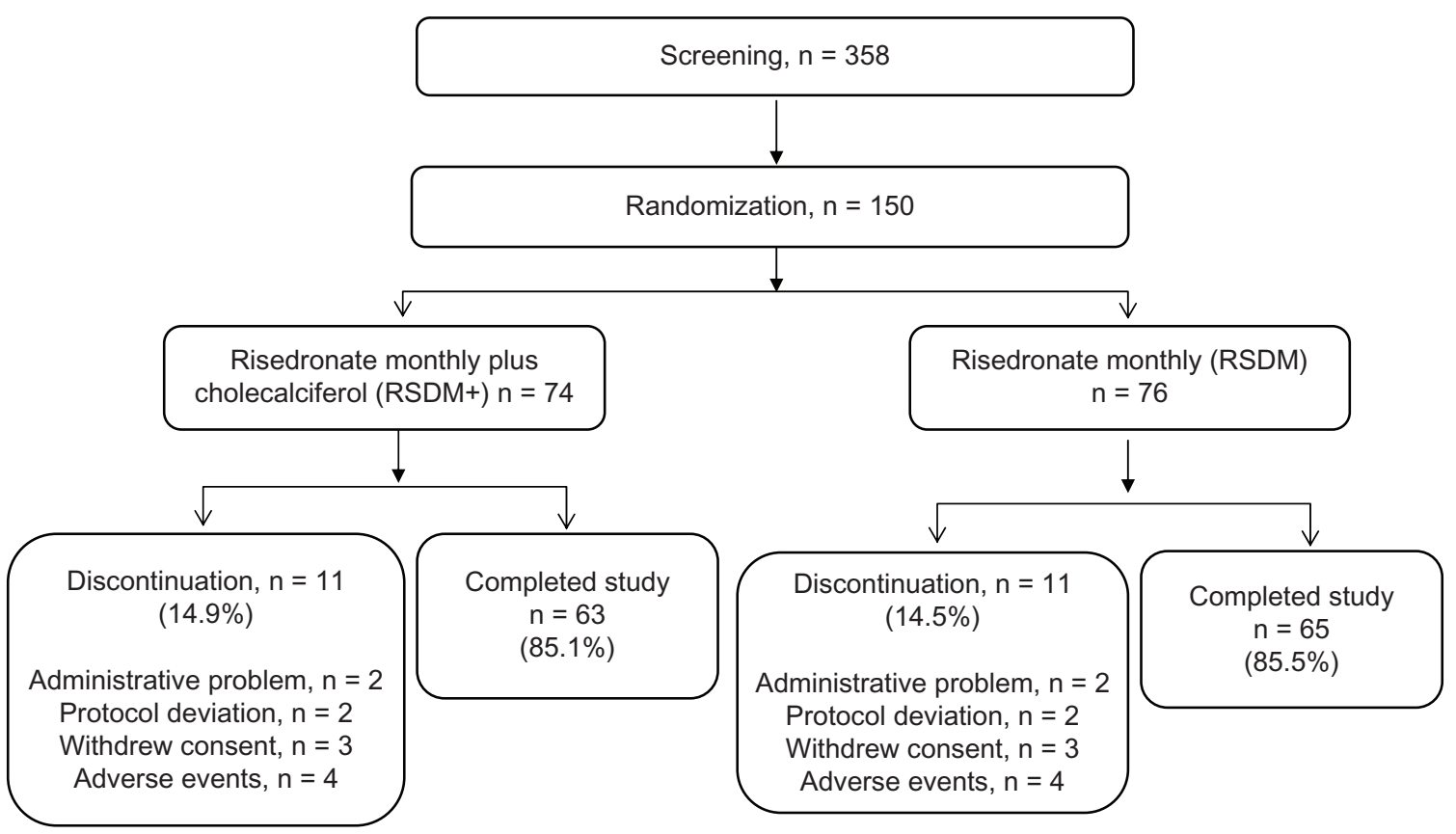

Figure I Participant disposition in 16-week study.

Note: Randomization and follow-up study. 
Table I Baseline characteristics of the participants

\begin{tabular}{|c|c|c|c|}
\hline & $\begin{array}{l}\text { RSDM+ }(n=74) \\
n(\%)\end{array}$ & $\begin{array}{l}\text { RSDM }(n=76) \text {, } \\
n(\%)\end{array}$ & $P$-value \\
\hline Age $($ mean $\pm S D)$ & $65.1 \pm 6.8$ & $65.7 \pm 8.3$ & 0.646 \\
\hline Alcohol & & & 0.438 \\
\hline Yes & $4(5.4)$ & $2(2.6)$ & \\
\hline No & $70(94.6)$ & $74(97.4)$ & \\
\hline \multicolumn{4}{|l|}{ Smoking } \\
\hline No & $74(100)$ & $76(100)$ & - \\
\hline BMI $\left(k g / m^{2}\right)$ & $23.8 \pm 2.2$ & $24.6 \pm 3.0$ & 0.055 \\
\hline 25(OH)D (ng/mL) & $17.8 \pm 6.6$ & $18.1 \pm 7.6$ & 0.755 \\
\hline \multicolumn{4}{|l|}{$25(\mathrm{OH}) \mathrm{D}$} \\
\hline$<20 \mathrm{ng} / \mathrm{mL}$ & 57 (77\%) & $53(69.7 \%)$ & 0.118 \\
\hline$<30 \mathrm{ng} / \mathrm{mL}$ & II (I4.9\%) & $13(17.1 \%)$ & 0.426 \\
\hline$\geq 30 \mathrm{ng} / \mathrm{mL}$ & $6(8.1 \%)$ & $10(13.2 \%)$ & 0.320 \\
\hline PTH (pg/mL) & $46.0 \pm 18.6$ & $38.0 \pm 13.7$ & 0.003 \\
\hline BSAP (U/L) & $32.6 \pm 9.8$ & $31.5 \pm 10.8$ & 0.551 \\
\hline CTX (ng/mL) & $0.42 \pm 0.21$ & $0.4 I \pm 0.24$ & 0.838 \\
\hline
\end{tabular}

Abbreviations: RSDM+, monthly risedronate and cholecalciferol; RSDM, monthly risedronate alone; SD, standard deviation; BMI, body mass index; $25(\mathrm{OH}) \mathrm{D}$, 25-hydroxyvitamin D; PTH, parathyroid hormone; BSAP, bone-specific alkaline phosphatase; CTX, carboxy-terminal collagen cross-links.

RSDM+ versus $30.2 \%$ of RSDM). Diarrhea was reported in $8.1 \%$ of the RSDM+ group and $7.9 \%$ of the RSDM. There were no laboratory adverse reports, including hypercalcemia and hypercalciuria.

\section{Discussion}

Many observational studies have demonstrated a relationship between higher serum $25(\mathrm{OH}) \mathrm{D}$ and $\mathrm{BMD}$, and a reduction in hip-fracture risk..$^{8,9}$ An Institute of Medicine report concluded that $25(\mathrm{OH}) \mathrm{D}$ equal to $20 \mathrm{ng} / \mathrm{mL}$ covers the requirements of $97.5 \%$ of the US population, and an adequate vitamin D intake is $600 \mathrm{IU}$ per day for children aged 1 year or older and $800 \mathrm{IU}$ per day for adults over 70 years of age. ${ }^{10}$ However, the

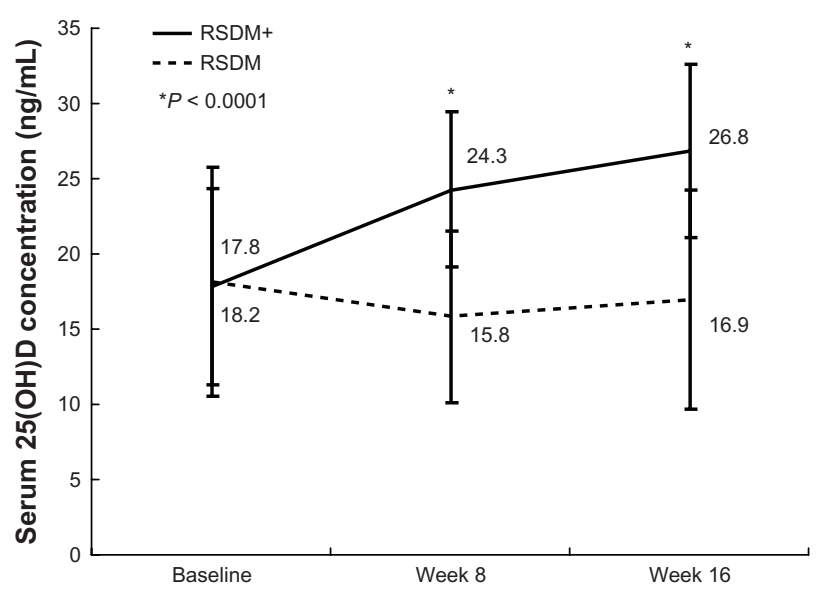

Figure 2 Mean changes in serum 25-hydroxyvitamin D (25[OH]D) concentration after 16 weeks of treatment.

Abbreviations: RSDM+, monthly risedronate and cholecalciferol; RSDM, monthly risedronate alone.

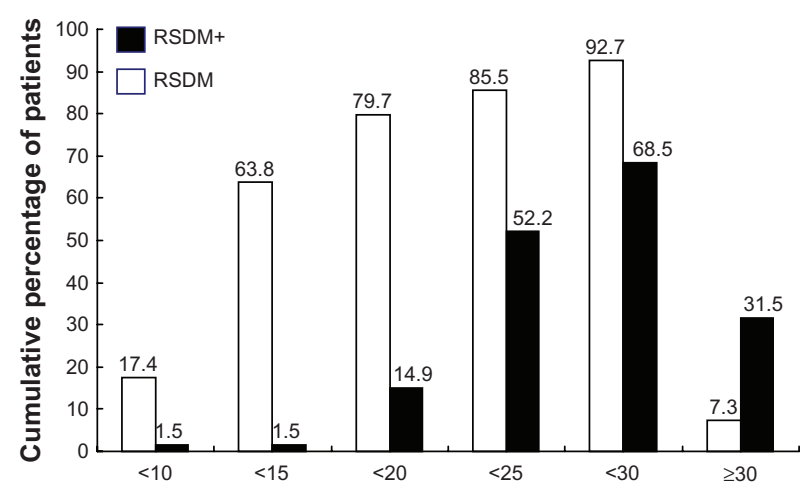

Figure 3 Percentages of participants with 25-hydroxyvitamin D level in different subcategories at week 16.

Abbreviations: RSDM+, monthly risedronate and cholecalciferol; RSDM, monthly risedronate alone.

definition of vitamin D insufficiency and recommendations for vitamin D intake are slightly different between the expert societies. The National Osteoporosis Foundation recommends 800-1000 IU vitamin D per day. ${ }^{11}$ The US Endocrine Society guidelines suggest that for adults aged 18 years or older, 1500-2000 IU per day may be needed to raise the serum $25(\mathrm{OH})$ D level consistently above $30 \mathrm{ng} / \mathrm{mL}$, which is considered to be the optimal level. ${ }^{12}$ To improve vitamin D intake, a single combined formulation containing bisphosphonates and vitamin $\mathrm{D}$ has been developed. A weekly dose of alendronate $70 \mathrm{mg}$ and cholecalciferol $2800 \mathrm{IU}$ increased the $25(\mathrm{OH}) \mathrm{D}$ level by $1.2 \mathrm{ng} / \mathrm{mL}$ only after 15 weeks. $^{7}$ A single-pill combination of weekly risedronate $35 \mathrm{mg}$ and cholecalciferol $5600 \mathrm{IU}$ increased 25(OH)D levels by $12.3 \mathrm{ng} / \mathrm{mL}{ }^{6}$ Therefore, a single-pill combination of bisphosphonates and cholecalciferol proved its efficacy in terms of vitamin D supplementation and antiresorptive effect. Supplementation of cholecalciferol 5600 IU has become a commonly used dosage for a single combined pill of weekly bisphosphonates.

It is known that patients prefer a less frequent and more convenient dosing regimen. ${ }^{13} \mathrm{~A}$ monthly dosing regimen has better therapeutic adherence than a weekly dosing regimen in postmenopausal osteoporosis. ${ }^{14}$ Thus, monthly risedronate was combined with cholecalciferol 30,000 IU, which is an estimated dose of 1000 IU per day in this trial. Even though the result was not from a head-to-head trial, monthly cholecalciferol 30,000 IU in this study showed less increase in $25(\mathrm{OH}) \mathrm{D}$ levels compared to that of the previously conducted trial with weekly cholecalciferol 5600 IU. Additionally, the percentage of vitamin D-insufficient patients $(<20 \mathrm{ng} / \mathrm{mL})$ decreased from $77 \%$ to $14.9 \%$ after 16 weeks of treatment with monthly 30,000 IU cholecalciferol, but decreased from $80.5 \%$ to $5.4 \%$ with weekly 5600 IU cholecalciferol. ${ }^{6}$ In another study, weekly administration of vitamin $\mathrm{D}$ resulted 


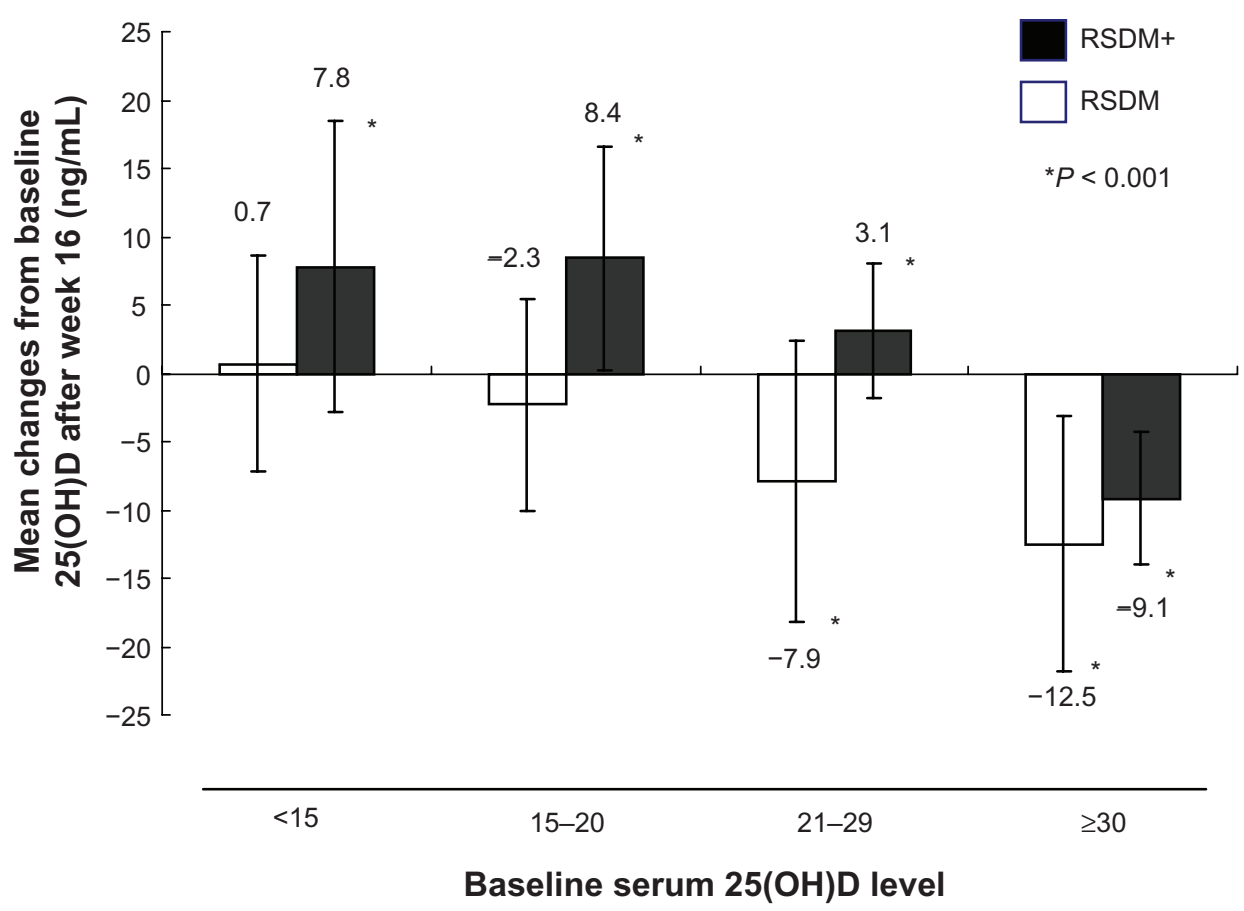

Figure 4 Mean changes in 25-hydroxyvitamin D (25[OH]D) level in each group with different baseline subcategories. Abbreviations: RSDM+, monthly risedronate and cholecalciferol; RSDM, monthly risedronate alone.

Table 2 Changes in PTH, calcium, phosphorus, and bone turnover markers between baseline and week 16 of treatment

\begin{tabular}{|c|c|c|c|}
\hline & \multicolumn{2}{|l|}{ Mean \pm SD } & \multirow[t]{2}{*}{$P$-value* } \\
\hline & RSDM+ & RSDM & \\
\hline \multicolumn{4}{|c|}{ PTH (pg/mL) } \\
\hline Baseline & $46.0 \pm 18.63$ & $38.0 \pm 13.72$ & 0.003 \\
\hline Week 16 & $36.7 \pm 18.55$ & $40.6 \pm 16.9$ & \\
\hline Change & $-9.06 \pm 20.32$ & $2.15 \pm 17.52$ & $0.0007^{* * * *}$ \\
\hline$P$-value** & 0.0005 & 0.3091 & \\
\hline \multicolumn{4}{|c|}{ Calcium (mg/dL) } \\
\hline Baseline & $8.96 \pm 0.37$ & $9.08 \pm 0.41$ & $0.047 \mid$ \\
\hline Week 16 & $8.92 \pm 0.43$ & $8.9 \pm 0.47$ & \\
\hline Change & $-0.02 \pm 0.34$ & $-0.18 \pm 0.48$ & $0.0317^{* * * *}$ \\
\hline$P$-value** & 0.6427 & 0.0036 & \\
\hline \multicolumn{4}{|c|}{ Phosphorus (mg/dL) } \\
\hline Baseline & $3.74 \pm 0.4 I$ & $3.82 \pm 0.47$ & 0.2501 \\
\hline Week 16 & $3.56 \pm 0.45$ & $3.65 \pm 0.44$ & \\
\hline Change & $-0.19 \pm 0.47$ & $-0.19 \pm 0.51$ & 0.9553 \\
\hline$P$-value** & 0.0018 & 0.0029 & \\
\hline \multicolumn{4}{|c|}{ BSAP (U/L) } \\
\hline Baseline & $32.5 \pm 9.83$ & $31.5 \pm 10.78$ & 0.5513 \\
\hline Week 16 & $18.3 \pm 4.6$ & $19.1 \pm 5.15$ & \\
\hline Change & $-14.2 \pm 8.07$ & $-12.2 \pm 9.67$ & 0.1891 \\
\hline$P$-value** & $<0.0001$ & $<0.0001$ & \\
\hline \multicolumn{4}{|c|}{ CTX (ng/mL) } \\
\hline Baseline & $0.42 \pm 0.21$ & $0.4 I \pm 0.24$ & $0.838 \mathrm{I}$ \\
\hline Week 16 & $0.13 \pm 0.10$ & $0.16 \pm 0.11$ & \\
\hline Change & $-0.32 \pm 0.25$ & $-0.31 \pm 0.20$ & 0.2735 \\
\hline$P$-value** & $<0.000$ I & $<0.0001$ & \\
\hline
\end{tabular}

Notes: *Unpaired $t$-test; **paired $t$-test; ***analysis of covariance. Abbreviations: RSDM+, monthly risedronate and cholecalciferol; RSDM, monthly risedronate alone; SD, standard deviation; PTH, parathyroid hormone; BSAP, bonespecific alkaline phosphatase; CTX, carboxy-terminal collagen cross-links. in a greater increase of serum $25(\mathrm{OH}) \mathrm{D}$ levels than monthly administration. ${ }^{15}$ Therefore, we can speculate that more cholecalciferol is needed for long-term interval treatment.

Recently, reports on increased risk for cardiovascular events associated with calcium supplementation have been controversial. ${ }^{16}$ In response to these concerns, the American Society for Bone and Mineral Research stated that food remains the best source of calcium and that supplements should only be used when adequate dietary intake of calcium cannot be achieved. Monthly bisphosphonate with cholecalciferol will be a good choice to provide convenience for patients who can take in adequate calcium from food and want less frequent medication.

The present study showed no increase in 25(OH)D levels in the vitamin D-sufficient group ( $\geq 30 \mathrm{ng} / \mathrm{mL}$ ), as shown in Figure 4. This could be attributed to 24-hydroxylation and formation of the inactive metabolite, although the precise physiological mechanism remains unclear. ${ }^{17}$ This change infers a good physiological regulation that protects against vitamin $\mathrm{D}$ intoxication, since the increase of serum 25(OH)D was lower in patients with higher initial serum 25(OH)D levels. ${ }^{18}$ These data suggest that monthly 30,000 IU cholecalciferol is safe in terms of vitamin D toxicity, even in vitamin $\mathrm{D}$-sufficient patients. The minimum dose of vitamin $\mathrm{D}$ that causes hypercalcemia in some healthy adults is 40,000 IU taken daily for many months. ${ }^{19}$ In fact, doses of $4000 \mathrm{IU} /$ day and 50,000 IU/week have been administered 
without toxicity. ${ }^{20}$ However, we need to check the long-term safety issues regarding vitamin D toxicity with monthly 30,000 IU cholecalciferol.

Recently, a single megadose of oral vitamin $\mathrm{D}_{3}$ has been associated with a higher risk of both falls and fractures in the first 3 months after dosing. ${ }^{21}$ Other studies have suggested that the dosing interval rather than the total dose might determine the outcome..$^{22,23}$ Therefore, changes in BMD and fracture reductions with monthly 30,000 IU cholecalciferol are needed to verify the efficacy of this regimen. This trial did not evaluate the change of BMD, but found that bone markers were significantly reduced, as much as in other studies. It has been estimated that change in BMD explains only $4 \%-28 \%$ of the reduction in vertebral fracture risk, as observed in antiresorptive agents. ${ }^{24}$ Early decrease in bone turnover is related to long-term increase in BMD in patients treated with bisphosphonates. ${ }^{25}$ The 55\%-60\% decrease in bone resorption measured by CTX at 3-6 months with risedronate therapy was significantly associated with reduction in vertebral fracture risk. ${ }^{26}$ The decrease of CTX at 4 months in this trial was 76\% (RSDM+) and $75 \%$ (RSDM), respectively. In terms of reduction in bone resorption, a single-pill combination of monthly risedronate with cholecalciferol is at least as good as the risedronate monthly regimen.

Our study showed that a monthly combination regimen decreased PTH levels. Among patients treated with bisphosphonates, PTH levels increased, presumably in response to a subclinical decrease in serum calcium caused by the inhibition of bone resorption. ${ }^{7}$ On the other hand, serum PTH decreased in the vitamin D-only treatment. ${ }^{15}$ These data suggest that monthly 30,000 IU cholesterol may attenuate the effect of bisphosphonate on the change of serum calcium, as shown in Table 2.

A limitation of this study may be the seasonal variation of $25(\mathrm{OH}) \mathrm{D}$. The treatment spanned from winter to summer. Circulating 25(OH)D levels vary seasonally due to seasonal fluctuations in sunlight ultraviolet B irradiation. ${ }^{27}$ Annual peak and nadir $25(\mathrm{OH}) \mathrm{D}$ levels occur in autumn and late winter or spring, respectively. However, patients in each group were matched by season to avoid confounding seasonal effects, and were provided with topical sunblock cream to limit their exposure to sunlight. The other limitation of this trial may be the duration of treatment. The short duration of our study prevented meaningful evaluation of BMD, locomotive function, and occurrence of fracture. Therefore, it is difficult to determine that a single-pill combination of risedronate and cholecalciferol would be more effective than a separate regimen as an osteoporosis treatment. However, it must be noted that coadministration in a single tablet reduced the proportion of patients with vitamin D insufficiency without reducing the antiresorptive efficacy of risedronate.

\section{Conclusion}

This once-monthly dosing may become an optimal choice for treatment of osteoporosis, providing convenience and efficacy in terms of decreased resorption and enhanced vitamin D status without toxicity.

\section{Acknowledgments}

This study was supported by Hanlim Pharmaceutical Co, Seoul, South Korea. All authors declare that they have no conflicts of interest.

\section{Disclosure}

The authors report no conflicts of interest in this work.

\section{References}

1. Reginster JY. Antifracture efficacy of currently available therapies for postmenopausal osteoporosis. Drugs. 2011;71(1):65-78.

2. Solomon DH, Avorn J, Katz JN, et al. Compliance with osteoporosis medications. Arch Intern Med. 2005;165(20):2414-2419.

3. Cooper C. Beyond daily dosing: clinical experience. Bone. 2006;38 Suppl 1:s13-s17.

4. Rosen CJ. Vitamin D insufficiency. N Engl J Med. 2011;364(3): 248-254.

5. Lee MK, Yim S, Lee ES, Park HM. Vitamin D perception gap survey between postmenopausal women with osteoporosis and physicians. Korean J Bone Metab. 2007;14:133-139. Korean.

6. Chung HY, Chin SO, Kang MI, et al. Efficacy of risedronate with cholecalciferol on 25-hydroxyvitamin D level and bone turnover in Korean patients with osteoporosis. Clin Endocrinol (Oxf). 2011;74(6): 699-704.

7. Recker R, Lips P, Felsenberg D, et al. Alendronate with and without cholecalciferol for osteoporosis: results of a 15-week randomized controlled trial. Curr Med Res Opin. 2006;22(9):1745-1755.

8. Bischoff-Ferrari HA, Dietrich T, Orav EJ, Dawson-Hughes B. Positive association between 25-hydroxyvitamin $\mathrm{D}$ levels and bone mineral density: a population-based study of younger and older adults. Am J Med. 2004;116(9):634-639.

9. Cauley JA, Parimi N, Ensrud KE, et al. Serum 25-hydroxyvitamin D and the risk of hip and nonspine fractures in older men. $J$ Bone Miner Res. 2010;25(3):545-553.

10. Institute of Medicine. Dietary Reference Intakes for Calcium and Vitamin D. Washington: National Academies Press; 2011.

11. National Osteoporosis Foundation. Physician's guide to the prevention and treatment of osteoporosis. 2013. Available from: http://www.nof. org/professionals/hcp/clinicians-guide. Accessed May 14, 2013.

12. Holick MF, Binkley NC, Bischoff-Ferrari HA, et al. Evaluation, treatment, and prevention of vitamin D deficiency: an Endocrine Society clinical practice guideline. J Clin Endocrinol Metab. 2011;96(7): 1911-1930.

13. Richter A, Anton SE, Koch P, Dennett SL. The impact of reducing dose frequency on health outcomes. Clin Ther. 2003;25(8): $2307-2335$. 
14. Chung YS, Lim SK, Chung HY, et al. Comparison of monthly ibandronate versus weekly risedronate in preference, convenience, and bone turnover markers in Korean postmenopausal osteoporotic women. Calcif Tissue Int. 2009;85(5):389-397.

15. Chel V, Wijnhove HAH, Smit JH, Ooms M, Lips P. Efficacy of different doses and time intervals of oral vitamin D supplementation with without calcium in elderly nursing home residents. Osteoporos Int. 2008;19(5):663-671.

16. Bolland MJ, Grey A, Avenell A, Gamble GD, Reid IR. Calcium supplements with or without vitamin D and risk of cardiovascular events: reanalysis of the Women's Health Initiative limited access dataset and meta-analysis. BMJ. 2011;342:d2040.

17. Wagner D, Hanwell HE, Schnabl K, et al. The ratio of serum 24, 25-dihydroxyvitamin $\mathrm{D}(2)$ to 25-hydroxyvitamin $\mathrm{D}(3)$ is predictive of 25-hydroxyvitamin $\mathrm{D}(3)$ response to vitamin $\mathrm{D}(3)$ supplementation. J Steroid Biochem Mol Biol. 2011;126(3-5):72-77.

18. Leidig-Bruckner G, Roth HJ, Bruckner T, Lorenz A, Raue F, FrankRaue K. Are commonly recommended dosages for vitamin D supplementation too low? Vitamin D status and effects of supplementation on serum 25-hydroxyvitamin D levels-an observational study during clinical practice conditions. Osteoporos Int. 2011;22(1):231-240.

19. Vieth R. Vitamin D toxicity, policy, and science. J Bone Miner Res. 2007;22 Suppl 2:V64-V68.

20. Vieth R, Chan PC, MacFarlane GD. Efficacy and safety of vitamin D3 intake exceeding the lowest observed adverse effect level. Am J Clin Nutr. 2001;73(2):288-294.
21. Sanders KM, Stuart AL, Williamson EJ, et al. Annual high-dose oral vitamin $\mathrm{D}$ and falls and fractures in older women. A randomized controlled trial. JAMA. 2010;303(18):1815-1822.

22. Trivedi D, Doll R, Khaw K. Effect of four monthly oral vitamin D supplementation on fractures and mortality in men and women living in the community: randomized double blind controlled trial. BMJ. 2003; 326(7387):469-475.

23. Smith H, Anderson F, Raphael H, Maslin P, Crozier S, Cooper C. Effect of annual intramuscular vitamin $\mathrm{D}$ on fracture risk in elderly men and women: a population-based, randomized, double-blind, placebocontrolled trial. Rheumatology (Oxford). 2007;46(12):1852-1857.

24. Cummings SR, Karpf DB, Harris F, et al. Improvement in spine bone density and reduction in risk of vertebral fractures during treatment with antiresorptive drugs. Am J Med. 2002;112(4):281-289.

25. Garnero P, Shih WJ, Gineyts E, Kalpf D, Delmas PD. Comparison of new biochemical markers of bone turnover in late postmenopausal osteoporotic women in response to alendronate treatment. J Clin Endocrinol Metab. 1994;79(6):1693-1700.

26. Eastell R, Barton I, Hannon RA, Chines A, Garnero P, Delmas PD. Relationship of early changes in bone resorption to the reduction in fracture risk with risedronate. J Bone Miner Res. 2003;18(6): 1051-1056.

27. Maxwell JD. Seasonal variation in vitamin D. Proc Nutr. 1994;53(3) $533-543$.
Clinical Interventions in Aging

\section{Publish your work in this journal}

Clinical Interventions in Aging is an international, peer-reviewed journal focusing on evidence-based reports on the value or lack thereof of treatments intended to prevent or delay the onset of maladaptive correlates of aging in human beings. This journal is indexed on PubMed Central, MedLine, the American Chemical Society's 'Chemical Abstracts

\section{Dovepress}

Service' (CAS), Scopus and the Elsevier Bibliographic databases. The manuscript management system is completely online and includes a very quick and fair peer-review system, which is all easy to use. Visit http://www.dovepress.com/testimonials.php to read real quotes from published authors. 